\title{
Extent, Type and Reasons for Adaptation and \\ Modification When Scaling-Up an Effective Physical Activity Program: Physical Activity 4 Everyone (PA4E1)
}

Matthew Mclaughlin ( $\square$ matthewmclaughlinemail@gmail.com )

University of Newcastle https://orcid.org/0000-0003-2870-8556

Elizabeth Campbell

Hunter New England Health: Hunter New England Local Health District

Rachel Sutherland

Hunter New England Health: Hunter New England Local Health District

Tom McKenzie

Hunter New England Health: Hunter New England Local Health District

Lynda Davies

Hunter New England Health: Hunter New England Local Health District

John Wiggers

Hunter New England Health: Hunter New England Local Health District

Luke Wolfenden

Hunter New England Health: Hunter New England Local Health District

\section{Research}

Keywords: program modification, program adaptation, fidelity, implementation science, scale-up, process evaluation, physical activity.

Posted Date: June 3rd, 2021

DOI: https://doi.org/10.21203/rs.3.rs-519998/v1

License: (a) (i) This work is licensed under a Creative Commons Attribution 4.0 International License. Read Full License 


\section{Abstract \\ Background}

Few studies have described the extent, type and reasons for making changes to a program prior to and during its delivery using a consistent taxonomy. Physical Activity 4 Everyone (PA4E1) is a secondary school physical activity program that was scaled-up for delivery to a greater number of schools. We aimed to describe the extent, type and reasons for changes to the PA4E1 program (the evidence-based physical activity practices, implementation support strategies and evaluation methods) made before its delivery at scale (adaptations) and during its delivery in a scale-up trial (modifications).

\section{Methods}

The Framework for Reporting Adaptations and Modifications-Enhanced (FRAME) was used to describe adaptations (planned and made prior to the scale-up trial) and modifications (made during the conduct of the trial). A list of adaptations was generated from a comparison of the efficacy and scale-up trials via published PA4E1 protocols, trial registrations and information provided by trial investigators. Monthly trial team meetings tracked and coded modifications in 'real-time' during the conduct of the scale-up trial. The extent, type and reasons for both adaptations and modifications were summarized descriptively.

\section{Results}

In total, 20 adaptations and 20 modifications were identified, these were to physical activity practices $(n=8 ; n=3)$, implementation support strategies $(n=6 ; n=16)$ and evaluation methods $(n=6, n=1)$, respectively. Few adaptations were 'fidelity inconsistent' $(n=2)$, made 'unsystematically' $(n=1)$ and proposed to have a 'negative' impact on the effectiveness of the program $(n=1)$. Reasons for the adaptations varied. Of the 20 modifications, all were 'fidelity consistent' and the majority were made 'proactively' $(n=12)$, though most were 'unsystematic' $(n=18)$. Fifteen of the modifications were thought to have a 'positive' impact on program effectiveness. The most common decision-maker in the modification process was the 'program manager' $(n=17)$. The main reason for modification was the 'available resources' $(n=14)$ of the PA4E1 Implementation Team. For both adaptations and modifications respectively, the most common goal was to 'improve fit with recipients' $(n=8 ; n=7)$.

\section{Conclusions}

A considerable number of adaptations and modifications were made for scale-up that could have important impacts on intervention effects and are important to the interpretation of trial findings.

\section{Trial Registration}

Australia New Zealand Clinical Trial Registry: ACTRN12617000681358

\section{Contributions To The Literature}


- This is the first study to use a consistent coding framework (FRAME) to categorize the extent, type and reasons for both adaptations for scale-up and modifications made during the implementation of the scaled-up trial.

- In line with previous research, we found that the program underwent a considerable number of adaptations for scale-up.

- Most adaptations and modifications were fidelity consistent and proposed to have a positive impact on the implementation of the program.

- Future research will use this data along with other process evaluation data (e.g. acceptability, appropriateness, feasibility) to explain the findings of the trial.

- It will be important for future programs to identify project management strategies to mitigate the occurrence of reactive operational modifications that are fidelity inconsistent.

\section{Introduction}

Physical activity has extensive benefits for health and society $(1,2)$. One in four adults and four in five adolescents globally are insufficiently active to meet aerobic physical activity guidelines $(3,4)$. While there are an abundance of evidence-based programs to address physical activity, many of these have been tested under optimal research conditions $(5,6)$, and few have successfully targeted adolescent physical activity $(7,8)$. As such, many programs previously tested have utilized technical expertise, skills, resources and infrastructure that are not common in realworld operational environments where they are intended to be implemented $(9,10)$. Further, research trials often recruit participant groups that differ markedly from those of the target population (11).

As physical activity programs examined in research trials are often unsuitable for replication in more real-world environments, they are frequently changed by end-users as part of efforts to make them more suitable for implementation and scale-up $(9,12)$. These changes can take two forms - adaptations to a program prior to it being delivered, and modifications that occur during the delivery of the program. Adaptation $(8,13)$ has been defined as a process of thoughtful and deliberate alteration to the design or delivery of a program, with the goal of improving its fit or effectiveness in a given context (13). Program adaptations can include both adaptations to the evidence-based practices and/or to the implementation support strategies provided to increase adoption of the practices in the setting (such as training for clinicians or teachers who will be delivering the program). Adaptations include those to core components of the program, cultural adaptations, mode of delivery adaptations, target audience adaptations and service setting adaptations (14). Modification has been defined as encompassing any change to a program, whether deliberately and proactively, or in reaction to unanticipated challenges that arise in the context of its delivery (13). Adaptations and modifications can also be made to evaluation methods.

Systematic reviews demonstrate that program adaptations are ubiquitous as part of efforts to scale-up programs in practice. For example, a systematic review of physical activity programs (8) reported that $100 \%$ of programs made adaptations to the program tested in an efficacy trial prior to undertaking a trial of its scale-up. The majority of adaptations focused on the 'delivery mode' of programs $(8,15,16)$, such as giving preference to online or telephone over face-to-face delivery modes, which are often undertaken to enable greater program reach (8). Understanding program adaptations and modifications is important as they can have significant implications to the effectiveness of programs $(9,12,17)$. They have been attributed, in part, to a phenomenon labeled 'voltage drop' whereby the effects of a program are reduced by $25-50 \%$ when they are implemented at scale in real world contexts $(8,16,17)$. However, they have also been hypothesized to improve the impact of programs. For example, improvements may be made by allowing tailoring of evidence-based programs and their implementation (i.e. the local culture, historical 
context, priorities and availability of funding, staffing and resources), strengthening key program components, reducing inequities by improving its cultural relevance, or reducing relative costs via delivery using less expensive modalities (12). Understanding the nature of program adaptations and modifications is also important for the development of explanations about how they may impact program implementation and outcomes as part of trial process evaluations (18).

The Framework for Reporting Adaptations and Modifications-Enhanced (FRAME) $(13,19)$ was recently developed to support the consistent documentation and reporting of program adaptations and modifications. It provides a taxonomy of classifying adaptations and modifications (13) including what is adapted/modified, the nature of the adaptation/modification, who participated in the adaptation/modification decision, for whom/ what is the adaptation/modification made and when it occurred. Despite the existence of FRAME and the need for consistent reporting, both adaptations made prior to program delivery and modifications made during the implementation are often poorly described in research reports $(13,15,20,21)$. That is, individual trials seldom report adaptations for scale-up (prior to program delivery) using consistent taxonomies (13), instead trials rely on descriptions of adaptations that can't be compared between trials (13).

A systematic review of 42 evidence-based public health programs that reported adaptations to the evidence-based program practices (15) found that the most frequent types of adaptation were tailoring (93\%) or adding elements (71\%). Most commonly these adaptations were to content (100\%), context (95\%), cultural (74\%) and/or delivery (62\%). While the review provides useful insights into the frequency of adaptations to the evidence based program practices, it does not explicitly include adaptations to the implementation support strategies used or the evaluation methods $(13,22)$. Also, the authors relied on published papers to retrospectively code adaptations to evidencebased program practices (15). A limitation of relying on published papers is that sometimes the extent, types, context and reasons for adaptations and modifications may be unclear or absent completely from these documents, remaining instead with those people involved in the scale-up process (15). Additionally, it is also unclear in many programs what modifications occur during delivery, and to the authors' knowledge, no physical activity studies have used a consistent taxonomy to report modifications during program delivery (23). Importantly, prior studies have also not routinely reported who was responsible for program adaptations or modifications, why these were undertaken, and if they were considered to contribute, or detract, from the effects of the program. Such information could be used to help interpret trial findings $(13,22)$.

In the absence of well-described adaptations prior to delivery and modifications during delivery, we present here a descriptive study of the adaptations and modifications made in the scale-up of an evidence based physical activity program targeting adolescents, Physical Activity 4 Everyone (PA4E1). PA4E1 is a secondary school physical activity program. After an efficacy trial, PA4E1 showed positive results (24-28), PA4E1 was adapted in preparation for scale-up (29). The PA4E1 program includes both an evidence-based program (consisting of seven school physical activity practices) and seven implementation support strategies offered to help schools implement these physical activity practices (implementation support). The aims of the current paper are:

1. To describe the extent, type and reasons for adaptations to PA4E1 that were made for scale-up to the physical activity practices, implementation support strategies and evaluation methods.

2. To describe the extent, type and reasons for modifications during the PA4E1 scale-up trial made to the physical activity practices, implementation support strategies and evaluation methods. 


\section{Methods}

This research has be conducted and reported in accordance with the requirements of the Standards for Reporting Implementation Studies (StaRI) Statement (Additional File 1).

\section{Ethical Approval}

The efficacy and scale-up trials have been registered at ACTRN12612000382875 and ACTRN12617000681358, respectively. Ethical approvals were sought from Hunter New England Human Research Ethics Committee (Ref No. 11/03/16/4.05), University of Newcastle (Ref No. H-2011-0210), NSW Department of Education and Communities (SERAP 2011111), Maitland Newcastle Catholic School Diocese, Broken Bay Catholic School Diocese, Lismore Catholic School Diocese, Armidale Catholic School Diocese, and the Aboriginal Health and Medical Research Council (AHMRC).

\section{Physical Activity 4 Everyone (PA4E1)}

An outline of the physical activity practices (evidence based program) for both the efficacy and scale-up trials are shown in Figure 1. The implementation support strategies offered to schools are outlined for both trials in Figure 2 $(25,28-32)$. As is best practice in implementation science (33), we distinguish between program components, separating the evidence-based program practices (the physical activity practices) from the implementation support strategies, which are designed to assist schools to implement the physical activity practices.

\section{Efficacy trial}

The evaluation methods of the PA4E1 efficacy trial have been reported in a trial protocol (25). Briefly, the PA4E1 efficacy trial was a 2-year (2012-2014) cluster randomized controlled trial involving 10 low-socioeconomic Australian secondary schools (five per group). Hunter New England Local Health District (HNELHD) led PA4E1 (34), supported by two other local health district delivery partners $(25,34)$ in a research-practice partnership with the University of Newcastle and New South Wales (NSW) Department of Education. PA4E1 had positive effects on students' device-measured moderate-to-vigorous physical activity and unhealthy weight gain $(24,25,28,32)$ and was deemed cost-effective (27). The PA4E1 program consisted of seven physical activity practices (Figure 1) to support students to be more physically active (the evidence-based program) and six implementation support strategies designed to embed the physical activity practices within the school environment (Figure 2).

\section{Scale-up trial}

The scale-up trial was a type III hybrid implementation-effectiveness trial. Methods have been reported in both a trial protocol (29) and a process evaluation protocol (31). The scale-up trial (2017-2019) tested the adapted PA4E1 program in a larger number of low-socioeconomic secondary schools $(n=49)$ across a larger geographic area (HNELHD leading three other local health districts, in a research-practice partnership with the University of Newcastle and NSW Department of Education (34)). Program schools were offered seven implementation support strategies (incorporating 23 sub-strategies) to support their adoption of seven physical activity practices (29-31). The scale-up trial recruited 49 schools (24 program, 25 control) (30).

\section{Adaptation process}


Adaptations were made in 2017 with the goal of scaling up the program (physical activity practices and implementation support strategies) employed in the efficacy trial and testing the effects again as part of a scale-up trial. The process has been reported in more detail elsewhere (29). The scale-up adaptation process sought to retain the effects of the original program by retaining components deemed as core (physical activity practices and implementation support strategies) $(24,25,28,32)$ while enabling greater reach (scaling up to more schools). Briefly, to adapt PA4E1 for scale-up, we used a four-stage iterative scale-up process, based on a review of existing models and factors for scaling up public health programs (35) and a scoping review of frameworks for adapting public health programs (36). Firstly, we identified barriers and enablers to the physical activity practices and implementation support strategies. Second, we mapped the identified barriers to the Theoretical Domains Framework (37) and the Behaviour Change Wheel (38). Thirdly, we prioritized the components of the program from the perspective of a health service requiring its delivery at scale, considering variables such as affordability, practicability and acceptability (39). Finally, the PA4E1 Expert Advisory Group (comprised of senior health service staff, senior academics, NSW Education sector partners and the PA4E1 project staff) reviewed the prioritized program (physical activity practices and implementation strategies) and made the final judgement regarding the design and components of the resulting PA4E1 program (29).

\section{Defining adaptation and modification}

We operationally defined changes to PA4E1 (inclusive of the physical activity practices, implementation support strategies and the evaluation methods) temporally, as either adaptations which were planned and made prior to the scale-up trial or modifications which were made during the conduct of the trial. The methods are reported by aim. Aim one focuses on adaptations (prior to scale) and aim two focuses on modifications (during implementation of the program in the scale-up trial).

\section{Aim 1: To describe the extent, type and reasons for adaptations to PA4E1 that were made for scale-up to the physical activity practices, implementation support strategies and evaluation methods.}

\section{Measures}

We used the FRAME framework to code the adaptations to the PA4E1 program made for scale-up (13). We applied the FRAME framework coding to the evidence-based practices (physical activity practices), the implementation support strategies (13) and the evaluation methods. The FRAME framework was used to provide a discrete set of codes for each category of adaptation (see Table 2 for a list of codes for each category). Additional coding categories (outlined below) were developed by the author team in line with methods from Rabin et al. (23) to report free-text descriptions of each adaptation.

Table 2 shows the adaptation categories utilized and the response codes. Briefly, these are:

- Description of the adaptation (open text)*

- What component of the PA4E1 program was the adaptation made to (the physical activity practices, implementation support strategies or evaluation methods)? 
- Was the adaptation proposed to have a positive, null or negative impact on the program effectiveness at the time of adaptation?

The following categories were coded for each adaptation from the FRAME framework (6):

- Were adaptations systematic or unsystematic?

Note: Based on the Model for Adaptation and Impact (MADI) framework (20), we revised the FRAME framework (13) terminology to remove the code "planned" and replace it with the code "systematic." This emphasizes the importance of how the modification was made (i.e., was it done using a systematic process which involved the use of theory to make the adaptation?)

- Were adaptations proactive or reactive?

- Who participated in the decision to adapt? (e.g. program manager, individual practitioners such as in-School Champion)

- What was the goal of adaptation? (e.g. improve feasibility, reduce cost)

- What was adapted? (i.e. context, training and evaluation, implementation and scale-up activity, content (including aspects of the way content was delivered))

- Context adaptations were made to what? (e.g. format, setting)

- At what level of delivery did adaptations occur? (e.g. unit level - an individual school)

- What is the nature of the content adaptation? (e.g. adding elements, shortening/condensing)

- Were adaptations fidelity consistent (relationship to core elements retained) or fidelity inconsistent?

- Reasons for the adaptation? (including socio-political, organization/setting, provider and recipient reasons)

Certain coding categories were considered 'not applicable' to the evaluation methods (as outlined in Table 2).

\section{Procedures}

Firstly, MM identified a list of adaptations between the efficacy and scale-up trial on physical activity practices, implementation support strategies and evaluation by triangulating data from a number of sources. The first source was published PA4E1 research papers: the trial protocol (25), 12 and 24-month outcome papers $(28,32)$ and costeffectiveness paper for the efficacy trial (27); and the trial protocol (29), process evaluation protocol (31) and 12month practice outcome paper (30) for the scale-up trial. Secondly, we drew upon the trial registries for both trials. Finally, to provide important context and resolve discrepancies in recorded adaptations, we drew on the historical knowledge of three authors (LD, EC and RS) who were involved in both trials through meetings with the lead author (MM).

To refine the initial codes, a consensus meeting was held between MM, TM, LD, RS, and EC. Following discussion, MM then finalized the coding for each of the adaptations. Finally, the final codes were agreed upon by email by MM, TM, LD, RS, and EC. Descriptive statistics for each adaptation category were calculated (e.g. the number and type of adaptations that were made).

To synthesize the adaptations, we calculated descriptive statistics for each adaptation category (e.g. the number and type of adaptations that were made) overall, and for adaptations made to physical activity practices, to implementation support strategies and to evaluation. 


\section{Aim 2: To describe the extent, type and reasons for modifications during the PA4E1 scale-up trial made to the physical activity practices, implementation support strategies and evaluation methods.}

\section{Procedures and measures}

We used the FRAME framework to describe and code modifications made during the delivery of the scaled-up PA4E1 program to the physical activity practices, the implementation support strategies and the evaluation methods.

We used the method as outlined in the process evaluation protocol (31). Throughout the 24-month program (20172019), Support Officers involved in the delivery of the program to schools and the PA4E1 Management Team involved in the day-to-day operations of the project continually tracked modifications to PA4E1 during the program in 'real-time' by adding them to a Microsoft Excel spreadsheet (23). A monthly meeting (up to 60 minutes) was held between the PA4E1 Management Team (including at least one Support Officer) to code the identified modifications onto the Stirman et al. (2013) framework for modifications in the same spreadsheet (19). MM subsequently updated the coding to reflect the additional categories included within the updated framework by Stirman et al., the FRAME framework $(13,19)$. This method of 'real-time ongoing coding' has previously been found to be feasible to track modifications (23). We used the same coding categories from Aim 1 for each modification (replacing the word adaptation for modification), as well as coding two additional categories. For the category of proposed impact on the program effectiveness at the time of modification (i.e. 'positive', 'null' or 'negative'), we coded this based on the predicted impact of the modification at the time of coding, rather than the actual or measured impact of the modification.

- Reason for the modification (open text)

- School Term the modification was first applied (within the 9 school term program)

At the end of the program, the final codes were collated by MM. The final codes were discussed and refined (by RS, EC, LD, TM) to reach consensus. Descriptive statistics for each modification category were calculated (e.g. the number and type of modifications that were made) overall and separately for physical activity practices, implementation support strategies and evaluation methods.

\section{Results}

Results are reported by aim.

\section{Aim 1: To describe the extent, type and reasons for adaptations to PA4E1 that were made for scale-up to the physical activity practices, implementation support strategies and evaluation methods.}


Table 1 descriptively summarizes the main program adaptations from efficacy trial to scale-up trial for individual physical activity practices and implementation support strategies, including the codes 'fidelity consistent or fidelity inconsistent', 'systematic or unsystematic' and 'proposed positive, negative or null impact on the project' (as described in the methods). For a more expanded description of adaptations made for the scale-up trial and their coding, see Additional File 2.

\section{Number of adaptations}

A total of 20 adaptations were made to scale-up PA4E1. Eight adaptations were to the school physical activity practices, six to the implementation support strategies and the remaining adaptations were to the evaluation methods $(n=6)$. Table 2 summarizes the codes according to the FRAME framework for physical activity practices, implementation support strategies and evaluation methods, respectively (13). Additional File 2 outlines each individual adaptation in detail and includes the full set of codes outlined in the methods.

The vast majority of adaptations were coded as 'systematic' ( $n=19)$, as they were made during the theory-informed iterative scale-up process. By definition, all adaptations $(n=20)$ were made 'proactively' rather than in response to an unknown event or circumstance. Two adaptations were deemed 'fidelity inconsistent', as the core elements or functions had changed as a result of the adaptation (13). Of the 14 adaptations to the practices and strategies, 12 were proposed to have a positive impact on program effectiveness. All adaptations involved both the 'Program Manager' and 'Treatment/Intervention Team' in the decision-making process, which included the PA4E1 Implementation Team (inclusive of the program manager, project staff and the expert advisory group) as described in the methods.

\section{Types of adaptations}

The goals and types of adaptations varied. The most common goals were to 'improve fit with recipients' $(n=8)$, 'improve feasibility' ( $n=5)$, 'improve effectiveness/outcomes' ( $n=4)$ and to 'reduce cost' $(n=3)$. Most adaptations were to 'content' $(n=13)$ and 'implementation and scale-up activities' $(n=12)$. Fewer adaptations were to 'training and evaluation' $(n=6)$ or 'contextual' $(n=1)$. All adaptations $(n=20)$ were made at the 'target intervention group' level, meaning that adaptations applied to all schools receiving the program, rather than certain schools or local health districts (e.g. 'individual', 'cohort' or 'individual practitioner' level). Content adaptations varied, including 'substituting' $(n=8)$ 'tailoring/tweaking/refining' $(n=3)$ and 'shortening/condensing' $(n=3)$.

\section{Reasons for adaptations}

The reasons for adaptations included the broad context of having 'funding or resource availability/allocation' ( $n=3$ ) and also the PA4E1 Implementation Team having 'available resources (funds, staff, technology, space)' ( $n=6)$. School and in-School Champions (i.e. 'recipients') reasons included cultural or religious norms ( $n=4)$, 'physical capacity' ( $n=2)$, 'motivation and readiness' $(n=2)$ and 'access to resources' $(n=2)$.

\section{Aim 2: To describe the extent, type and reasons for modifications during the PA4E1 scale-up trial made to the physical activity practices, implementation support strategies and evaluation methods.}


Table 3 provides a brief description of each modification made to the physical activity practices and implementation support strategies during the scale-up trial delivery.

\section{Number of modifications}

A total of 20 modifications were made during the delivery of the scale-up trial of PA4E1 from 2017-2019. Of these, 16 modifications were made to the implementation support strategies, three to the physical activity practices and one to the evaluation methods. All modifications were deemed 'fidelity consistent' and most modifications were proposed to have a positive impact on the effectiveness of the program $(n=15)$. Table 4 summarizes the modification codes according to the FRAME framework (13). Additional File 3 outlines each individual modification in detail and includes the full set of codes (as outlined in the methods).

\section{Types of modifications}

The vast majority of modifications were 'unsystematic' $(n=18)$, because most modifications did not make deliberate use of theory to make the modification. Two modifications made to support sustainability used theory and therefore were deemed systematic. Most modifications $(n=12)$ were made 'proactively', however eight modifications were made in response to an unknown event or circumstance and were therefore coded as 'reactive'. Most modifications involved the 'program manager' $(n=17)$. 'Individual practitioners' participated in half of all decisions $(n=10)$. Other groups and individuals participated in the decision making process less frequently, including the whole PA4E1 Implementation Team 'treatment/intervention team' ( $n=3)$, local health districts 'administrator' ( $n=2)$ and in-School Champion 'recipients' $(n=1)$.

The goals and types of modifications varied. The most common goals were to 'improve fit with recipients' ( $n=7)$, 'increase satisfaction' ( $n=6)$, 'improve effectiveness/outcomes' ( $n=5)$, 'increase reach or engagement' ( $n=4)$ and to 'increase retention' ( $n=4)$. All modifications were to either 'content' $(n=14)$ or 'training and evaluation' $(n=6)$. The nature of content modifications varied, including 'adding elements' ( $n=5)$, 'tailoring/tweaking/refining' $(n=3)$ and 'removing/skipping elements' $(n=2)$. Most modifications $(n=15)$ were made across all schools, in all local health districts, and were therefore coded the 'target intervention group' level. The remaining modifications occurred at particular local health districts 'cohort level' $(n=3)$ or individual schools 'clinic/unit level' $(n=4)$.

\section{Reasons for modifications}

Reasons for modifications were primarily related to the 'available resources' (funds, staff, tech, space) $(n=14)$ of the PA4E1 Implementation Team, i.e. the 'provider'. The second most common reason was schools and in-School Champions (i.e. recipient) 'motivation and readiness' $(n=8)$. Further reasons for modification were few, but included 'historical context' $(n=1)$ and the 'social context' $(n=1)$ surrounding the 'PA4E1 Implementation Team'.

\section{Discussion}

\section{Principal Findings}

To the authors' knowledge, this is the first study to use a taxonomy to comprehensively report the number, types and reasons for both adaptations made to scale-up a program and also the modifications that occurred during the delivery of the scaled-up program. Our findings indicate that 20 adaptations were made to the PA4E1 program for scale-up $(25,28,32)$, including eight adaptations to the physical activity practices, six to the implementation support strategies and six to the evaluation methods. Most adaptations were proposed to have a positive impact on 
the effectiveness of the program $(n=12)$. Additionally, 20 modifications were made during the delivery of the scaledup program, of which 16 were proposed to have a positive impact on the effectiveness of the program. Most modifications were to the implementation support strategies $(n=16)$. Given that the use of adaptation and modifications data is being encouraged to explain the findings of scale-up trials (20), the findings of this study provide valuable data, together with detailed process evaluation data (31) to help to explain the findings of the scale-up trial $(18,31)$.

'Funding and resource availability' was a common reason adaptations and modifications were made. The occurrence of adaptations as part of a research trial, involving the original trial developers, and with a good understanding of the programs and its mechanism of effect may also explain the frequency with which they were fidelity consistent, and thought to have a beneficial impact. The findings underscore the importance of selecting programs that are congruent with the available resources to deliver them at scale, and in doing so, reduce the need for significant adaptations. The use of scalability assessment tools may assist policy makers and practitioners can assist with this process (40).

Both adaptations and modifications to the scale-up of PA4E1 were primarily made to 'improve fit with recipients' (i.e. schools). Most adaptations were coded as 'fidelity consistent' and 'systematic' (i.e. informed by theory). Such findings are perhaps unsurprising, given they occurred in the context of a funded trial, involving the original trial developers with a good understanding of the program and its mechanism and who employed a considered process to informing adaptations (29). It is also consistent with previous reviews of public health programs (15).

Adaptability is a key component of scalable programs, where optimal adaptations are those which are made to fit different contexts and environments while retaining fidelity consistency $(12,13,21,40)$.

Modifications, in contrast to adaptations, were found to be 'unsystematic', likely reflecting the rapid and reactive contexts in which these changes were likely made by end-users. However, modifications to the program were all coded as 'fidelity consistent', and so retain the intended core functions of the program (outlined in Additional File 2). School staff may have, as a result of the training undertaken as part of the scale-up strategy, or via their existing tacit knowledge, have a good understanding of how the program may impact on the intended outcome and been mindful of this when undertaking modifications. Further research is warranted to explore and better explain such findings.

Reviews of scaled-up physical activity (8) and obesity programs (16) that characterized the nature of adaptations made for scale-up, concluded that adaptations to the 'mode of delivery' of programs were particularly prevalent (8, 14, 16). Similarly, we found 13 content adaptations to scale-up PA4E1 and 14 content modifications during delivery of the scaled-up PA4E1. Content adaptations and modifications include those which use an alternate way to 'deliver aspects of the treatment' (i.e. alternate delivery mode), for example, the use of a website to deliver resources rather than distributing paper copies of resources $(8,16)$, demonstrating the adaptable nature of the program. While changes to the delivery modes or content modifications may be perceived as fidelity consistent or improving the overall impacts of a program, for example, by increasing reach and the number of people who may benefit, they may also reduce the absolute effect size of a program $(8,41,42)$. That is, the 'voltage drop' phenomena whereby the effect sizes of physical activity programs are reduced at scale, may be acceptable from a population perspective if the scaled-up program is capable of reaching and so benefiting (due to delivery mode adaptations) more people, at lower relative cost. Taking a population-level perspective is therefore important when weighing and assessing the potential impact of adaptations or modifications. 


\section{Strengths and Limitations}

It has been recommended that researchers consider potential causal pathways of modifications, considering both the intended and unintended impacts of modifications on outcomes (20). In line with our process evaluation protocol (31), we have comprehensively described the extent, type and reasons for adaptations and modifications to PA4E1. A strength of this study is the use of real-time tracking of modifications during delivery to record deviations from the planned protocols, which is expected during trial delivery but often not documented well. Indeed, we found the method to be feasible and informative within our study. We found coding using the FRAME to initially be quite difficult, despite the existence of a coding manual (43). We would suggest to future researchers to consider annotating the FRAME framework coding for their own context $(13,43)$. We also emphasize the importance of going beyond published papers to generate a list of adaptations. By also using the knowledge of those involved in both the efficacy and scale-up trials, we were able to code more accurately the reasons for adaptation. Finally, we used the FRAME to report adaptations and modifications to the physical activity practices, implementation support strategies and evaluation methods. Subsequent to our data analysis, the FRAME-IS (Implementation Strategy) was released which is designed for implementation support strategies and organized into modules. The use of both the FRAME (13) and FRAME-IS (22) may have improved our coding of adaptations and reduced the frequency of consensus meetings required. Additional support to use FRAME to code adaptations and modifications to evaluation methods may also be useful.

\section{Conclusions}

Adaptations and modifications to public health programs are often poorly described and may be more prevalent than currently reported. We used a taxonomy to transparently describe adaptations made before scale-up and modifications made during implementation. We found 20 adaptations made for scale-up and a further 20 modifications during the delivery of the scaled-up program. Making modifications that retain core components but better suit a particular context (program adaptability) is considered to be an important component of successfully scaled-up programs. However, it will be important for future programs to identify project management strategies to mitigate the occurrence of reactive operational modifications that are fidelity inconsistent.

Describing the extent, type and reasons for adaptations and modifications made to public health programs provides valuable process evaluation data to help explain the findings of the program. For example, the data may be used to explain the expected reduction in effect size when they are scaled-up. The comprehensive and transparent description of adaptations and modifications will assist us to generate hypotheses relating to the trial process evaluation and implementation outcome data, which will be explored further.

\section{Abbreviations}

AHMRC: Aboriginal Health and Medical Research Council

FRAME: Framework for Reporting Adaptations and Modifications-Enhanced

FRAME-IS: Framework for Reporting Adaptations and Modifications-Enhanced - Implementation HMRI: Hunter Medical Research Institute

HNELHD: Hunter New England Local Health District

Page 12/32 
MADI: Model for Adaptation Design and Impact

NESA: New South Wales Education Standards Authority

NSW: New South Wales

PA: Physical Activity

PA4E1: Physical Activity 4 Everyone

PE: Physical Education

RT4T: Resistance Training 4 Teens

SAAFE: Supportive, Active, Autonomous, Fair and Enjoyable

SERAP: State Education Research Applications Process

\section{Declarations}

\section{Ethics approval and consent to participate}

The efficacy and scale-up trial have been prospectively registered at ACTRN12612000382875 and ACTRN12617000681358, respectively. The efficacy trial was approved by the Hunter New England Area Human Research Ethics Committee (11/03/16/4.0) and the University of Newcastle Human Research Ethics Committee (H2011-0210). For the scale-up trial, ethical approvals were sought from the Hunter New England Human Research Ethics Committee (Ref No. 11/03/16/4.05), the University of Newcastle (Ref No. H-2011-0210), the NSW Department of Education and Communities (SERAP 2011111), the Maitland Newcastle Catholic School Diocese, the Broken Bay Catholic School Diocese, the Lismore Catholic School Diocese, the Armidale Catholic School Diocese, and the Aboriginal Health and Medical Research Council.

\section{Consent for publication}

Parental consent, including consent for publication in both trials was obtained as a requirement of Hunter New England Area Human Research Ethics Committee and the University of Newcastle Human Research Ethics Committee. All data is aggregated and no individual data is presented.

\section{Trial Registration}

Australia New Zealand Clinical Trial Registry: ACTRN12617000681358

Date of Registration: $12^{\text {th }}$ May, 2017

Date of first participant enrollment: $1^{\text {st }}$ November 2017

https://www.anzctr.org.au/Trial/Registration/TrialReview.aspx?id=372870.

\section{Availability of data and materials}

The datasets analyzed during the current study are available from the corresponding author on reasonable request. 


\section{Competing interests}

The authors declare that they have no competing interests.

\section{Funding}

This project is funded by the NSW Ministry of Health, Translational Research Grant Scheme. The NSW Ministry of Health has not had any role in the design of the study as outlined in this protocol and will not have a role in data collection, analysis of data, interpretation of data and dissemination of findings. This work was also supported by Cancer Council New South Wales. The project received infrastructure support from the Hunter Medical Research Institute (HMRI). RS is supported by a NHMRC TRIP Fellowship (APP1150661). LW is supported by a NHMRC Career Development Fellowship (APP1128348), Heart Foundation Future Leader Fellowship (101175) and a Hunter New England Clinical Research Fellowship.

\section{Authors' contributions}

MM conceived the design of the study. MM, LC and LW refined the research questions. RS, EC, LW and JW obtained funding for the research. MM led the ongoing data collection, with significant contributions from EC, RS, TM and LD. MM led the data analysis. MM, EC, RS, TM and LD were involved in the coding of modifications. MM led the development of the manuscript. All authors provided critical comment on multiple versions of the manuscript and approved the final manuscript.

\section{Acknowledgements}

The authors would like to acknowledge the staff from the Central Coast, Mid-North Coast, South-West Sydney and Hunter New England Local Health Districts involved in delivering this trial.

\section{References}

1. 2018 Physical Activity Guidelines Advisory Committee. 2018 Physical Activity Guidelines Advisory Committee Scientific Report. U.S. Department of Health and Human Services; 2018.

2. The International Society for Physical Activity and Health (ISPAH). The Bangkok Declaration on Physical Activity for Global Health and Sustainable Development. British Journal of Sports Medicine. 2017;51(19):138991.

3. Guthold R, Stevens GA, Riley LM, Bull FC. Global trends in insufficient physical activity among adolescents: a pooled analysis of 298 population-based surveys with 1.6 million participants. The Lancet Child \& Adolescent Health. 2019.

4. Guthold R, Stevens GA, Riley LM, Bull FC. Worldwide trends in insufficient physical activity from 2001 to 2016 : a pooled analysis of 358 population-based surveys with 1.9 million participants. The Lancet Global Health. 2018;6(10):e1077-e86.

5. Finch M, Jones J, Yoong S, Wiggers J, Wolfenden L. Effectiveness of centre-based childcare interventions in increasing child physical activity: a systematic review and meta-analysis for policymakers and practitioners. Obesity reviews : an official journal of the International Association for the Study of Obesity. 2016;17(5):412-28.

6. Yoong SL, Wolfenden L, Clinton-McHarg T, Waters E, Pettman TL, Steele E, et al. Exploring the pragmatic and explanatory study design on outcomes of systematic reviews of public health interventions: a case study on obesity prevention trials. Journal of public health (Oxford, England). 2014;36(1):170-6. 
7. Love R, Adams J, van Sluijs EMF. Are school-based physical activity interventions effective and equitable? A meta-analysis of cluster randomized controlled trials with accelerometer-assessed activity. Obesity reviews : an official journal of the International Association for the Study of Obesity. 2019.

8. Lane C, McCrabb S, Nathan N, Naylor P-J, Bauman A, Milat A, et al. How effective are physical activity interventions when they are scaled-up: a systematic review. International Journal of Behavioral Nutrition and Physical Activity. 2021;18(1):16.

9. Milat AJ, King L, Bauman AE, Redman S. The concept of scalability: increasing the scale and potential adoption of health promotion interventions into policy and practice. Health Promotion International. 2013;28(3):285-98.

10. Milat AJ, Bauman AE, Redman S, Curac N. Public health research outputs from efficacy to dissemination: a bibliometric analysis. BMC Public Health. 2011;11(1):934.

11. Averitt AJ, Weng C, Ryan P, Perotte A. Translating evidence into practice: eligibility criteria fail to eliminate clinically significant differences between real-world and study populations. npj Digital Medicine. 2020;3(1):67.

12. Chambers DA, Glasgow RE, Stange KC. The dynamic sustainability framework: addressing the paradox of sustainment amid ongoing change. Implementation Science. 2013;8(1):117.

13. Wiltsey Stirman S, Baumann AA, Miller CJ. The FRAME: an expanded framework for reporting adaptations and modifications to evidence-based interventions. Implementation Science. 2019;14(1):58.

14. Chambers DA, Norton WE. The Adaptome: Advancing the Science of Intervention Adaptation. American journal of preventive medicine. 2016;51(4 Suppl 2):S124-31.

15. Escoffery C, Lebow-Skelley E, Haardoerfer R, Boing E, Udelson H, Wood R, et al. A systematic review of adaptations of evidence-based public health interventions globally. Implementation science : IS. 2018;13(1):125.

16. McCrabb S, Lane C, Hall A, Milat A, Bauman A, Sutherland R, et al. Scaling-up evidence-based obesity interventions: A systematic review assessing intervention adaptations and effectiveness and quantifying the scale-up penalty. Obesity Reviews. 2019;20:964-82.

17. Movsisyan A, Arnold L, Evans R, Hallingberg B, Moore G, O'Cathain A, et al. Adapting evidence-informed complex population health interventions for new contexts: a systematic review of guidance. Implementation Science. 2019;14(1):105.

18. Moore GF, Audrey S, Barker M, Bond L, Bonell C, Hardeman W, et al. Process evaluation of complex interventions: Medical Research Council guidance. BMJ : British Medical Journal. 2015;350.

19. Stirman SW, Miller CJ, Toder K, Calloway A. Development of a framework and coding system for modifications and adaptations of evidence-based interventions. Implementation Science. 2013;8(1):65.

20. Kirk MA, Moore JE, Wiltsey Stirman S, Birken SA. Towards a comprehensive model for understanding adaptations' impact: the model for adaptation design and impact (MADI). Implementation Science. 2020;15(1):56.

21. Yoong SL, Bolsewicz K, Grady A, Wyse R, Sutherland R, Hodder RK, et al. Adaptation of public health initiatives: expert views on current guidance and opportunities to advance their application and benefit. Health Education Research. 2020;35(4):243-57.

22. Miller CJ, Barnett ML, Baumann AA, Gutner CA, Wiltsey-Stirman S. The FRAME-IS: a framework for documenting modifications to implementation strategies in healthcare. Implementation Science. 2021;16(1):36.

Page 15/32 
23. Rabin BA, McCreight M, Battaglia C, Ayele R, Burke RE, Hess PL, et al. Systematic, Multimethod Assessment of Adaptations Across Four Diverse Health Systems Interventions. Frontiers in Public Health. 2018;6(102).

24. Hollis JL, Sutherland R, Campbell L, Morgan PJ, Lubans DR, Nathan N, et al. Effects of a 'school-based' physical activity intervention on adiposity in adolescents from economically disadvantaged communities: secondary outcomes of the 'Physical Activity 4 Everyone' RCT. Int J Obes (Lond). 2016;40(10):1486-93.

25. Sutherland R, Campbell E, Lubans DR, Morgan PJ, Okely AD, Nathan N, et al. A cluster randomised trial of a school-based intervention to prevent decline in adolescent physical activity levels: study protocol for the 'Physical Activity 4 Everyone' trial. BMC Public Health. 2013;13(1):57.

26. Sutherland R, Campbell L, Lubans D, Morgan P, Okely AD, Nathan N, et al. 'Physical Activity 4 Everyone' schoolbased intervention to prevent decline in adolescent physical activity levels: 12 month (mid-intervention) report on a cluster randomised trial. British Journal of Sports Medicine. 2015.

27. Sutherland R, Reeves P, Campbell E, Lubans DR, Morgan PJ, Nathan N, et al. Cost effectiveness of a multicomponent school-based physical activity intervention targeting adolescents: the 'Physical Activity 4 Everyone' cluster randomized trial. The international journal of behavioral nutrition and physical activity. 2016;13:94.

28. Sutherland RL, Campbell EM, Lubans DR, Morgan PJ, Nathan NK, Wolfenden L, et al. The Physical Activity 4 Everyone Cluster Randomized Trial: 2-Year Outcomes of a School Physical Activity Intervention Among Adolescents. American journal of preventive medicine. 2016;51(2):195-205.

29. Sutherland R, Campbell E, Nathan N, Wolfenden L, Lubans DR, Morgan PJ, et al. A cluster randomised trial of an intervention to increase the implementation of physical activity practices in secondary schools: study protocol for scaling up the Physical Activity 4 Everyone (PA4E1) program. BMC Public Health. 2019;19(1):883.

30. Sutherland R, Campbell E, McLaughlin M, Nathan N, Wolfenden L, Lubans DR, et al. Scale-up of the Physical Activity 4 Everyone (PA4E1) intervention in secondary schools: 12-month implementation outcomes from a cluster randomized controlled trial. International Journal of Behavioral Nutrition and Physical Activity. 2020;17(1):100.

31. McLaughlin M, Duff J, Sutherland R, Campbell E, Wolfenden L, Wiggers J. Protocol for a mixed methods process evaluation of a hybrid implementation-effectiveness trial of a scaled-up whole-school physical activity program for adolescents: Physical Activity 4 Everyone (PA4E1). Trials. 2020;21(1):268.

32. Sutherland R, Campbell E, Lubans DR, Morgan PJ, Okely AD, Nathan N, et al. 'Physical Activity 4 Everyone' school-based intervention to prevent decline in adolescent physical activity levels: 12 month (mid-intervention) report on a cluster randomised trial. British Journal of Sports Medicine. 2015;50(8):488-95.

33. Pinnock H, Barwick M, Carpenter CR, Eldridge S, Grandes G, Griffiths CJ, et al. Standards for Reporting Implementation Studies (StaRI): explanation and elaboration document. BMJ Open. 2017;7(4):e013318.

34. Wolfenden L, Yoong SL, Williams CM, Grimshaw J, Durrheim DN, Gillham K, et al. Embedding researchers in health service organizations improves research translation and health service performance: the Australian Hunter New England Population Health example. J Clin Epidemiol. 2017;85:3-11.

35. Milat AJ, Bauman A, Redman S. Narrative review of models and success factors for scaling up public health interventions. Implementation Science. 2015;10(1):113.

36. Escoffery C, Lebow-Skelley E, Udelson H, Boing EA, Wood R, Fernandez ME, et al. A scoping study of frameworks for adapting public health evidence-based interventions. Translational behavioral medicine. 2018.

37. Cane J, O'Connor D, Michie S. Validation of the theoretical domains framework for use in behaviour change and implementation research. Implementation Science. 2012;7(1):37. 
38. Michie S, van Stralen MM, West R. The behaviour change wheel: a new method for characterising and designing behaviour change interventions. Implementation Science : IS. 2011;6:42-.

39. Michie S, Atkins L, West R. The Behaviour Change Wheel: A Guide to Designing Interventions. . Great Britain: Silverback Publishing; 2014.

40. Lee K, Milat A, Grunseit A, Conte K, Wolfenden L, Bauman A. The Intervention Scalability Assessment Tool: a pilot study assessing five interventions for scalability. Public health research \& practice. 2020;30(2).

41. Stewart AL, Gillis D, Grossman M, Castrillo M, Pruitt L, McLellan B, et al. Diffusing a research-based physical activity promotion program for seniors into diverse communities: CHAMPS III. Prev Chronic Dis. 2006;3(2):A51.

42. Hardy LL, Mihrshahi S, Gale J, Nguyen B, Baur LA, O’Hara BJ. Translational research: are community-based child obesity treatment programs scalable? BMC Public Health. 2015;15(1):652.

43. Stirman. FRAME Coding Manual. Accessed: 22/04/2021. Available from: http://med.stanford.edu/fastlab/research/adaptation.html. 2020.

44. Lubans DR, Lonsdale C, Cohen K, Eather N, Beauchamp MR, Morgan PJ, et al. Framework for the design and delivery of organized physical activity sessions for children and adolescents: rationale and description of the 'SAAFE' teaching principles. International Journal of Behavioral Nutrition and Physical Activity. 2017;14(1):24.

45. Lubans DR, Morgan PJ, Callister R, Collins CE, Plotnikoff RC. Exploring the mechanisms of physical activity and dietary behavior change in the program $\mathrm{x}$ intervention for adolescents. The Journal of adolescent health : official publication of the Society for Adolescent Medicine. 2010;47(1):83-91.

46. Kennedy SG, Smith JJ, Morgan PJ, Peralta LR, Hilland TA, Eather N, et al. Implementing Resistance Training in Secondary Schools: A Cluster Randomized Controlled Trial. Medicine and science in sports and exercise. 2018;50(1):62-72.

\section{Tables}

Table 1: Adaptations to each specific component of PA4E1 efficacy trial made for the scale-up trial, including adaptations to individual school physical activity practices and implementation support strategies offered to schools. 


\begin{tabular}{|c|c|c|c|c|c|}
\hline $\begin{array}{l}\text { Name of efficacy } \\
\text { trial program } \\
\text { component }\end{array}$ & $\begin{array}{l}\text { Following } \\
\text { adaptation, } \\
\text { name of scale- } \\
\text { up trial program } \\
\text { component }\end{array}$ & $\begin{array}{l}\text { Descriptive summary of } \\
\text { main adaptations from } \\
\text { efficacy trial to scale-up } \\
\text { trial }\end{array}$ & $\begin{array}{l}\text { Fidelity } \\
\text { consistent? }\end{array}$ & Systematic? & $\begin{array}{l}\text { Proposed } \\
\text { positive } \\
(+), \\
\text { negative } \\
(-) \text { or null } \\
(0) \\
\text { impact } \\
\text { on the } \\
\text { project }\end{array}$ \\
\hline $\begin{array}{l}\text { Practice 1: } \\
\text { Teaching } \\
\text { strategies to } \\
\text { maximize } \\
\text { students' } \\
\text { physical activity } \\
\text { in health and } \\
\text { physical } \\
\text { education (PE) } \\
\text { lessons }\end{array}$ & $\begin{array}{l}\text { Practice 1: } \\
\text { Quality PE } \\
\text { lessons }\end{array}$ & $\begin{array}{l}\text { Change of focus } \\
\text { from focusing on "Active" } \\
\text { (which is a single principle } \\
\text { within "SAAFE" PE lesson } \\
\text { guidelines) to all "SAAFE" } \\
\text { principles PE Lessons (i.e. } \\
\text { Supportive, Active, } \\
\text { Autonomous, Fair and } \\
\text { Enjoyable) (44). } \\
\quad \text { Though pedometers } \\
\text { were made available to } \\
\text { schools, this became less } \\
\text { of a focus and was not a } \\
\text { mandatory part of the } \\
\text { practice. } \\
\quad \text { The PE Department } \\
\text { used documented } \\
\text { principles or guidelines. } \\
\quad \text { PE teacher should } \\
\text { participate in peer } \\
\text { observation of a practical } \\
\text { PE lesson at least once per } \\
\text { year. }\end{array}$ & $X$ & $\checkmark$ & + \\
\hline $\begin{array}{l}\text { Practice 2: } \\
\text { Development and } \\
\text { monitoring of } \\
\text { student physical } \\
\text { activity plans } \\
\text { within PE lessons }\end{array}$ & $\begin{array}{l}\text { Practice 2: } \\
\text { Student PA } \\
\text { plans }\end{array}$ & $\begin{array}{l}\text { As well as Grade 8's } \\
\text { in year two, Grade 7's } \\
\text { should also develop a } \\
\text { physical activity plan in } \\
\text { year two. } \\
\quad \text { Goals were to be } \\
\text { reviewed yearly, not termly. }\end{array}$ & $\checkmark$ & $\checkmark$ & + \\
\hline $\begin{array}{l}\text { Practice 3: } \\
\text { Enhanced school } \\
\text { sport program }\end{array}$ & $\begin{array}{l}\text { Practice 3: } \\
\text { Enhanced } \\
\text { school sport } \\
\text { program }\end{array}$ & $\begin{array}{l}\text { Changed from } \\
\text { 'Program X' (45) to the } \\
\text { 'Resistance Training } 4 \\
\text { Teens (RT4T)' program } \\
\text { (46). } \\
\text {. RT4T was offered } \\
\text { as accredited training by } \\
\text { the NSW Department of } \\
\text { Education. }\end{array}$ & $\checkmark$ & $\checkmark$ & + \\
\hline $\begin{array}{l}\text { Practice 4: } \\
\text { Development/ } \\
\text { modification of } \\
\text { school policies }\end{array}$ & $\begin{array}{l}\text { Practice 5: } \\
\text { School PA policy } \\
\text { or procedure }\end{array}$ & $\begin{array}{l}\quad \text { The policy must } \\
\text { include the provision of at } \\
\text { least } 150 \text { minutes of } \\
\text { moderate to vigorous- } \\
\text { intensity physical activity } \\
\text { during school time for all } \\
\text { students in Grade } 7-10 \text {. }\end{array}$ & $\checkmark$ & $\checkmark$ & + \\
\hline
\end{tabular}


Practice 5:

Physical activity

programs during

school breaks
Practice 4: Recess and lunchtime PA

Changed to 3 days per week (from 2), ideally with at least one activity targeting girls specifically.

Schools were also asked to provide access to physical activity equipment to students at least three days per week.

Practice 6:

Promotion of community physical activity providers (community links)
Practice 6: Links with community PA providers

\section{Specification that schools form three links with community physical activity providers that go beyond the promotion of the provider.}

. It was desirable that at least one of the community links made were to promote free or low-cost options in the community.

Schools were asked to use multiple modes to promote (e.g. newsletter, parent app).

- This replaced a oneday community physical activity provider expo (as more feasible and sustained)
Practice 7: Parent engagement
Practice 7:

Communicating PA messages to all parents
- $\quad$ Schools were asked to use multiple modes to communicate the messages (e.g. newsletter, parent app).
Strategy 1 : Inschool physical activity consultant
Strategy 2 and 3: Embedded school staff: inSchool Champion and External implementation support

\section{- $\quad$ External physical} activity consultant replaced by an in-School Champion (an existing PE teacher within the school) who was supported by a Health Promotion Support Officer employed by the respective local health district.

\section{In-School Champions were funded \$400 a fortnight.}

$\quad$ Support Officer and
in-School Champion
maintained contact
through face-to-face
meetings, email and phone
according to the schedule
documented within the
support strategy.

Support Officer and through face-to-face meetings, email and phone documented within the support strategy. 


\begin{tabular}{|c|c|c|c|c|c|}
\hline & & $\begin{array}{l}\quad \text { Support Officer was } \\
\text { co-located in the same } \\
\text { local health district with in- } \\
\text { School Champions. }\end{array}$ & & & \\
\hline $\begin{array}{l}\text { Strategy 2: } \\
\text { Establishing } \\
\text { leadership and } \\
\text { support }\end{array}$ & $\begin{array}{l}\text { Strategy 1: } \\
\text { Executive and } \\
\text { leadership } \\
\text { support }\end{array}$ & $\begin{array}{l}\quad \text { Less total } \\
\text { committee members in the } \\
\text { scale-up trial (i.e. no } \\
\text { requirement for student, } \\
\text { parent, Head PE teacher } \\
\text { and community } \\
\text { representative) and } \\
\text { include both the in-School } \\
\text { Champion and school } \\
\text { executive. }\end{array}$ & $\checkmark$ & $\checkmark$ & + \\
\hline $\begin{array}{l}\text { Strategy 3: } \\
\text { Teacher training }\end{array}$ & $\begin{array}{l}\text { Strategy 4: } \\
\text { Teacher } \\
\text { professional } \\
\text { learning }\end{array}$ & $\begin{array}{l}\text { PE Teacher training } \\
\text { via a website ( } 6 \text { modules) } \\
\text { rather than } 3 \text { face-to-face } \\
\text { sessions. } \\
\text { WESA (New South } \\
\text { Wales Education } \\
\text { Standards Authority) } \\
\text { accreditation attached to } \\
\text { online training. } \\
\quad \text { Specific training for } \\
\text { writing a physical activity } \\
\text { policy for in-School } \\
\text { Champions. } \\
\text { Three days training } \\
\text { for in-School Champion. }\end{array}$ & $\checkmark$ & $\checkmark$ & + \\
\hline $\begin{array}{l}\text { Strategy 4: } \\
\text { Resources }\end{array}$ & $\begin{array}{l}\text { Strategy 5: } \\
\text { Resources }\end{array}$ & $\begin{array}{l}\quad \text { Paper-based } \\
\text { resources were replaced by } \\
\text { a website housing } \\
\text { documentation and } \\
\text { resources, except for } \\
\text { printed posters outlining } \\
\text { the SAAFE principles (for } \\
\text { Practice 1). } \\
\quad \quad \text { Less total } \\
\text { equipment provided, five } \\
\text { gymsticks and an } \\
\text { equipment voucher were } \\
\text { provided to schools rather } \\
\text { than providing all the } \\
\text { \$6000 equipment. } \\
\quad \quad \text { Promotional } \\
\text { materials were not issued } \\
\text { as part of the support } \\
\text { strategy but instead for the } \\
\text { completion of evaluation } \\
\text { measures. }\end{array}$ & $\checkmark$ & $\checkmark$ & - \\
\hline Strategy 5: & Strategy 6: & $\begin{array}{c}\text { Support Officers } \\
\text { Page } 20 / 32\end{array}$ & $\checkmark$ & $\checkmark$ & + \\
\hline
\end{tabular}




\begin{tabular}{|c|c|c|c|c|c|}
\hline Prompts & $\begin{array}{l}\text { Provision of } \\
\text { prompts and } \\
\text { reminders }\end{array}$ & $\begin{array}{l}\text { reminded in-School } \\
\text { Champions to implement } \\
\text { the program rather than } \\
\text { the in-school consultant } \\
\text { reminding teachers. } \\
\text { Automated prompts } \\
\text { to in-School Champions } \\
\text { and PE teachers delivered } \\
\text { via the program website. }\end{array}$ & & & \\
\hline $\begin{array}{l}\text { Strategy 6: } \\
\text { Intervention } \\
\text { implementation } \\
\text { performance }\end{array}$ & $\begin{array}{l}\text { Strategy 7: } \\
\text { Implementation } \\
\text { performance } \\
\text { monitoring and } \\
\text { feedback }\end{array}$ & $\begin{array}{l}\quad \text { Feedback was } \\
\text { automated via the } \\
\text { program website and was } \\
\text { directly against the } \\
\text { physical activity practice } \\
\text { milestones (as practice } \\
\text { implementation builds } \\
\text { over two school years and } \\
\text { is designed to be } \\
\text { ongoing). } \\
\quad \text { Feedback was } \\
\text { automatically sent to } \\
\text { (website registered) in- } \\
\text { School Champions and } \\
\text { Principals. } \\
\quad \text { No direct } \\
\text { observations were } \\
\text { undertaken by the Support } \\
\text { Officer. }\end{array}$ & $\checkmark$ & $\checkmark$ & 0 \\
\hline
\end{tabular}

\section{Footnotes}

A total of 20 adaptations were made to scale-up PA4E1, including seven to individual physical activity practices and six to implementation support strategies. A further six adaptations were made to the evaluation methods and one adaptation to all physical activity practices, not included in this table. For a description of each coding category, see the methods and FRAME (13). See Additional File 2 for a complete dataset of the types and reasons for each modification according to the FRAME (13).

Abbreviations: PE, Physical Education; SAAFE, Supportive Active Autonomous Fair Enjoyable; RT4T, Resistance Training 4 Teens; NSW, New South Wales.; NESA, NSW Education Standards Authority.

Table 2: FRAME framework (13) modification codes for adaptations from efficacy to scale-up trial. 


\begin{tabular}{|c|c|c|c|c|c|}
\hline $\begin{array}{l}\text { Modification } \\
\text { Categories }\end{array}$ & Code & $\begin{array}{l}\text { Physical } \\
\text { Activity } \\
\text { Practices } \\
\text { n (\%) }\end{array}$ & $\begin{array}{l}\text { Implementation } \\
\text { Support } \\
\text { Strategies } \\
\mathrm{n}(\%)\end{array}$ & $\begin{array}{l}\text { Evaluation } \\
\text { methods } \\
N(\%)\end{array}$ & $\begin{array}{l}\text { Total } \\
\text { (practices, } \\
\text { strategies } \\
\text { and } \\
\text { evaluation) } \\
\mathrm{n}(\%) \text { ** }\end{array}$ \\
\hline \multirow{3}{*}{$\begin{array}{l}\text { Program } \\
\text { Component? }\end{array}$} & Physical Activity Practices & $8(100)$ & N/A & $\mathrm{N} / \mathrm{A}$ & $8(40)$ \\
\hline & \multirow{2}{*}{$\begin{array}{l}\text { Implementation Support } \\
\text { Strategies }\end{array}$} & N/A & $6(100)$ & $\mathrm{N} / \mathrm{A}$ & $6(30)$ \\
\hline & & N/A & $\mathrm{N} / \mathrm{A}$ & $6(100)$ & $6(30)$ \\
\hline \multirow{4}{*}{$\begin{array}{l}\text { Proposed impact on } \\
\text { the project? }\end{array}$} & Positive & $8(100)$ & $4(66)$ & $\mathrm{N} / \mathrm{A}$ & $12(86)$ \\
\hline & Negative & $0(0)$ & $1(17)$ & $\mathrm{N} / \mathrm{A}$ & $1(7)$ \\
\hline & Null & $0(0)$ & $1(17)$ & $\mathrm{N} / \mathrm{A}$ & $1(7)$ \\
\hline & Not applicable & $0(0)$ & $0(0)$ & $6(100)$ & $6^{*}$ \\
\hline \multirow{3}{*}{$\begin{array}{l}\text { Relationship to } \\
\text { fidelity/core } \\
\text { elements? }\end{array}$} & Fidelity consistent & $7(88)$ & $5(83)$ & N/A & $12(86)$ \\
\hline & Fidelity inconsistent & $1(13)$ & $1(17)$ & N/A & $2(14)$ \\
\hline & Not applicable & $0(0)$ & $0(0)$ & $6(100)$ & 6 \\
\hline \multirow{2}{*}{$\begin{array}{l}\text { Were adaptations } \\
\text { systematic or } \\
\text { unsystematic? }\end{array}$} & Systematic & $7(88)$ & $6(100)$ & $6(100)$ & $19(95)$ \\
\hline & Unsystematic & $1(13)$ & $0(0)$ & $0(0)$ & $1(5)$ \\
\hline \multirow{2}{*}{$\begin{array}{l}\text { Were adaptations } \\
\text { proactive or } \\
\text { reactive? }\end{array}$} & Proactive & $8(100)$ & $6(100)$ & $6(100)$ & $20(100)$ \\
\hline & Reactive & $0(0)$ & $0(0)$ & $0(0)$ & $0(0)$ \\
\hline \multirow{3}{*}{$\begin{array}{l}\text { Who participated in } \\
\text { the decision to } \\
\text { modify?* }\end{array}$} & Program Manager & $8(100)$ & $6(100)$ & $6(100)$ & $20(100)$ \\
\hline & \multirow{2}{*}{$\begin{array}{l}\text { Treatment/Intervention } \\
\text { Team }\end{array}$} & $8(100)$ & $6(100)$ & $6(100)$ & $20(100)$ \\
\hline & & $0(0)$ & $0(0)$ & $0(0)$ & $0(0)$ \\
\hline \multirow{9}{*}{$\underset{*}{\text { What was the goal? }}$} & Improve fit with recipients & $4(50)$ & $4(67)$ & $0(0)$ & $8(57)$ \\
\hline & Improve feasibility & $0(0)$ & $5(83)$ & $0(0)$ & $5(36)$ \\
\hline & Improve & $3(38)$ & $1(17)$ & $0(0)$ & $4(29)$ \\
\hline & 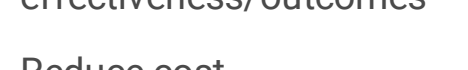 & $0(0)$ & $3(50)$ & $0(0)$ & $3(21)$ \\
\hline & Mencice cose & $1(13)$ & $0(0)$ & $0(0)$ & $1(7)$ \\
\hline & engagement & $1(13)$ & $0(0)$ & $0(0)$ & $1(7)$ \\
\hline & Increase satisfaction & $0(0)$ & $0(0)$ & $0(0)$ & $0(0)$ \\
\hline & Other codes & $0(0)$ & $0(0)$ & $6(100)$ & 6 \\
\hline & Not applicable & & & & \\
\hline \multirow[t]{2}{*}{ What is adapted?* } & Content & $7(88)$ & $6(100)$ & $0(0)$ & $13(65)$ \\
\hline & & $0(0)$ & $6(100)$ & $6(100)$ & $12(60)$ \\
\hline
\end{tabular}




\begin{tabular}{|c|c|c|c|c|c|}
\hline & $\begin{array}{l}\text { Implementation and scale- } \\
\text { up activities }\end{array}$ & $0(0)$ & $0(0)$ & $6(100)$ & $6(30)$ \\
\hline & Training and Evaluation & $1(13)$ & $0(0)$ & $0(0)$ & 1 (5) \\
\hline & Contextual & & & & \\
\hline Contextual & Format & $1(13)$ & $0(0)$ & N/A & $1(100)$ \\
\hline made to what? & Setting & $0(0)$ & $0(0)$ & $\mathrm{N} / \mathrm{A}$ & $0(0)$ \\
\hline & Personnel & $0(0)$ & $0(0)$ & $\mathrm{N} / \mathrm{A}$ & $0(0)$ \\
\hline & Population & $0(0)$ & $0(0)$ & $\mathrm{N} / \mathrm{A}$ & $0(0)$ \\
\hline & Not applicable & $7(88)$ & $6(100)$ & $6(100)$ & 19 \\
\hline At what level of & Target Intervention Group & $8(100)$ & $6(100)$ & $6(100)$ & $20(100)$ \\
\hline adaptations made? & (dil scillouls) & $0(0)$ & $0(0)$ & $0(0)$ & $0(0)$ \\
\hline & sharing a characteristic) & $0(0)$ & $0(0)$ & $0(0)$ & $0(0)$ \\
\hline & $\begin{array}{l}\text { Clinic Unit/level (individual } \\
\text { schools) }\end{array}$ & & & & \\
\hline What is the nature & Substituting & $3(38)$ & $4(67)$ & $0(0)$ & $8(62)$ \\
\hline adaptation?* & Tailoring/tweaking/refining & $0(0)$ & $0(0)$ & $0(0)$ & $3(23)$ \\
\hline & Lengthening/extending & $2(25)$ & $0(0)$ & $0(0)$ & $2(15)$ \\
\hline & 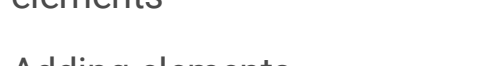 & $1(13)$ & $1(17)$ & $0(0)$ & $2(15)$ \\
\hline & 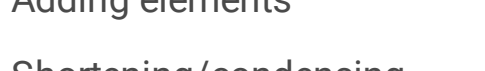 & $1(13)$ & $2(33)$ & $0(0)$ & $3(23)$ \\
\hline & Not applicable & $1(13)$ & $0(0)$ & $6(100)$ & 7 \\
\hline Reasons - socio- & None (no reason) & $4(50)$ & $5(83)$ & $0(0)$ & $9(64)$ \\
\hline context) ${ }^{\star}$ & Funding or resource & $2(25)$ & $1(17)$ & $0(0)$ & $3(21)$ \\
\hline & 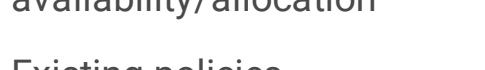 & $2(25)$ & $0(0)$ & $0(0)$ & $1(7)$ \\
\hline & Existing poircies & $0(0)$ & $0(0)$ & $0(0)$ & $1(7)$ \\
\hline & Societal/cultural norms & $0(0)$ & $0(0)$ & $0(0)$ & $0(0)$ \\
\hline & Not applicable & $0(0)$ & $0(0)$ & $6(100)$ & 6 \\
\hline Reasons - & None (no reason) & $8(100)$ & $0(0)$ & $0(0)$ & $8(57)$ \\
\hline (i.e. PA4E1 & Available resources (funds, & $0(0)$ & $6(100)$ & $0(0)$ & $6(43)$ \\
\hline Team)* & stan, lecin, space) & $0(0)$ & $0(0)$ & $0(0)$ & $0(0)$ \\
\hline & Not applicable & $0(0)$ & $0(0)$ & $6(100)$ & 6 \\
\hline Reasons - provider & None (no reason) & $8(100)$ & $6(100)$ & $0(0)$ & $14(100)$ \\
\hline District)* ${ }^{*}$ & Not applicable & $0(0)$ & $0(0)$ & $6(100)$ & 6 \\
\hline
\end{tabular}




\begin{tabular}{|llllll|}
$\begin{array}{l}\text { Reasons - recipient } \\
\text { (i.e. schools and in- }\end{array}$ & None (no reason) & $4(50)$ & $2(33)$ & $0(0)$ & $6(43)$ \\
$\begin{array}{l}\text { School } \\
\text { Champions)* }\end{array}$ & Cultural or religious norms & $0(0)$ & $4(66)$ & $0(0)$ & $4(29)$ \\
& Physical capacity & $2(25)$ & $0(0)$ & $0(0)$ & $2(14)$ \\
& Motivation and readiness & $1(13)$ & $1(17)$ & $0(0)$ & $2(14)$ \\
& Access to resources & $2(25)$ & $0(0)$ & $0(0)$ & $0(0)$ \\
Other codes & $0(0)$ & $0(0)$ & $6(10)$ & 6 \\
\hline
\end{tabular}

\section{Footnotes}

*Percentages may not sum to $100 \%$, and $n$ values may not add up to the number of adaptations ( $N=20)$ because multiple codes within this category may be applied to each adaptation.

** 'Not applicable (N/A)' category not included in denominator to calculate percentages.

Abbreviations: Not applicable (N/A).

Additional File 2 outlines each individual adaptation in detail and includes the full set of codes as outlined in the methods.

Table 3: Modifications to each component of PA4E1 scale-up trial made during the delivery of the program (practices and implementation support strategies). 


\begin{tabular}{|c|c|c|c|c|c|}
\hline $\begin{array}{l}\text { Modification } \\
\text { Number } \\
\text { (Term } \\
\text { initiated) }\end{array}$ & $\begin{array}{l}\text { Program Component(s) and brief } \\
\text { description of modification made } \\
\text { during scale-up Trial }\end{array}$ & $\begin{array}{l}\text { Fidelity } \\
\text { Consistent? }\end{array}$ & Systematic? & $\begin{array}{l}\text { Proactive } \\
\text { modification? }\end{array}$ & $\begin{array}{l}\text { Proposed } \\
\text { positive } \\
(+), \\
\text { negative } \\
(-) \text { or null } \\
(0) \\
\text { impact } \\
\text { on the } \\
\text { project? }\end{array}$ \\
\hline $1(1)$ & $\begin{array}{l}\quad \text { Implementation Strategy 2: } \\
\text { For the entire duration of the } \\
\text { program, funding for the in-School } \\
\text { Champions was increased from } \\
\text { AUD } \$ 350 \text { a fortnight to AUD } \$ 400 \text {. }\end{array}$ & $\checkmark$ & $x$ & $\checkmark$ & + \\
\hline $2(1)$ & $\begin{array}{l}\quad \text { Implementation Strategy 5: } \\
\text { Instead of simply providing the } \\
\text { physical resources to schools, they } \\
\text { were issued as 'incentives' upon } \\
\text { completion of training, though all } \\
\text { schools ended up receiving the } \\
\text { resources as they all completed } \\
\text { the necessary training. All schools } \\
\text { ended up receiving the resources if } \\
\text { they wanted them. }\end{array}$ & $\checkmark$ & $X$ & $\checkmark$ & + \\
\hline $3(1)$ & $\begin{array}{l}\quad \text { Implementation Strategy 3: } \\
\text { Due to staff turnover, for some } \\
\text { schools, their Support Officer was } \\
\text { not co-located within same Local } \\
\text { Health District. }\end{array}$ & $\checkmark$ & $\mathrm{X}$ & $x$ & - \\
\hline $4(1)$ & $\begin{array}{l}\quad \text { Implementation Strategy 3: } \\
\text { Due to staff turnover, for some } \\
\text { schools, their Support Officer not } \\
\text { trained in physical education } \\
\text { teaching. }\end{array}$ & $\checkmark$ & $\mathrm{X}$ & $x$ & - \\
\hline $5(2)$ & $\begin{array}{l}\quad \text { Implementation Strategy } 6: \\
\text { Prompting emails were supposed } \\
\text { to be sent reminding users to } \\
\text { complete professional } \\
\text { development. However, these were } \\
\text { not sent to PE Teachers or in- } \\
\text { School Champions if they } \\
\text { registered after the first term of the } \\
\text { program. An error in the website } \\
\text { coding. }\end{array}$ & $\checkmark$ & $X$ & $x$ & - \\
\hline $6(4)$ & $\begin{array}{l}\quad \text { Implementation Strategy } 5 \text { : } \\
\text { Additional resources were made } \\
\text { available, these were a set of } 30 \\
\text { pedometers made available to } \\
\text { schools who wanted them. Not all } \\
\text { schools wanted them. The PA4E1 } \\
\text { had } 3 \text { sets available in total. }\end{array}$ & $\checkmark$ & $x$ & $\checkmark$ & + \\
\hline $7(4)$ & $\begin{array}{l}\quad \text { Implementation Strategy 3: } \\
\text { Enhanced school sport training } \\
\text { delivered by Support Officers to a } \\
\text { single school as Department of } \\
\text { Education training dates had } \\
\text { expired. In-School Champions and } \\
\text { PE Teachers unable to receive }\end{array}$ & $\checkmark$ & $X$ & $X$ & + \\
\hline
\end{tabular}


accreditation for this ad-hoc training.

8 (4) Implementation Strategy 4
Extra day of face-to-face training
held halfway through the program
(Term 6). While a second day of
face-to-face training was outlined
within the study protocol (Table 2
(29)). School Champions were not
made aware of this until Term 4
the program. This was because
the program team were unsure
about available resources.

9 (5) $\begin{aligned} & \quad \text { Implementation Strategy 5 } \\ & \text { Facebook Group created by in- } \\ & \text { School Champions to facilitate } \\ & \text { resource, discussion and } \\ & \text { knowledge exchange. }\end{aligned}$

$10(5)$

. Practice 2: Physical activity plans to be completed by Grade 7 only in the second half of the program, not both Grade 7 and 8 (as originally described in the study protocol - see Table 2 (29)).

4:Face-to-face training was
repeated for schools unable to
attend the centralized training held
for all schools. This training was
delivered locally to the schools at
a location and time that suited the
schools, to reduce travel times for
the in-School Champions.

$12(6)$ . Implementation Strategy 5: Additional physical resources for enhanced school sport training were sent to a single school who requested them from their Support Officer.

$\begin{array}{ll}13(6) \quad \text { Practice 1: Lesson } \\ & \text { observation forms could be } \\ & \text { submitted either through the } \\ \text { website form or uploaded as a } & \\ \text { word document (new). }\end{array}$

\section{$14(7)$}

. Implementation Strategy 7:

All schools were sent incorrect

$\checkmark \quad x$

$\begin{array}{lll}X & \checkmark\end{array}$

$\begin{array}{lll}x & \end{array}$
. 


\begin{tabular}{|c|c|c|c|c|c|}
\hline & $\begin{array}{l}\text { Strategy 1-7: Extension of the } \\
\text { whole implementation support } \\
\text { program by one school term, } \\
\text { extending the program from' } 8 \\
\text { school terms to } 9 \text { school terms. } \\
\text { However, schools were not } \\
\text { provided additional funds for } \\
\text { release of the in-School Champion } \\
\text { (Implementation Strategy 2) }\end{array}$ & & & & \\
\hline $17(7)$ & $\begin{array}{l}\quad \text { Implementation Strategy 4: } \\
\text { Extra day of face-to-face training } \\
\text { held at the end of the program to } \\
\text { support sustainability (Term 9). }\end{array}$ & $\checkmark$ & $x$ & $\checkmark$ & + \\
\hline $18(8)$ & $\begin{array}{l}\quad \text { Implementation Strategy 7: } \\
\text { Sustainability reports, similar to } \\
\text { termly surveys and feedback } \\
\text { reports, were designed to assist } \\
\text { schools to plan strategies for } \\
\text { sustaining the PA4E1 program in } \\
\text { their school beyond the life of the } \\
\text { research project. These were } \\
\text { issued via email to be completed } \\
\text { by in-School Champions in liaison } \\
\text { with their school Principal. }\end{array}$ & $\checkmark$ & $\checkmark$ & $\checkmark$ & + \\
\hline 19 (8) & $\begin{array}{l}\quad \text { Implementation Strategy } 1 \\
\text { and 7: All School Principals were } \\
\text { offered a face-to-face meeting in } \\
\text { Term } 8 \text { to explain their schools } 24 \\
\text { month sustainability report. }\end{array}$ & $\checkmark$ & $x$ & $\checkmark$ & + \\
\hline
\end{tabular}

\section{Footnotes}

A total of 20 modifications were made during the scale-up of PA4E1, including three to physical activity practices and 16 to implementation support strategies. A further adaptation was made to the evaluation methods, not included in this table. Term initiated refers to the School Term (1-9) that the modification was first made. For a description of each coding category, see the methods section and FRAME (13). See Additional File 3 for a complete dataset of the types and reasons for each modification according to the FRAME (13). Abbreviations: PE, Physical Education; NSW, New South Wales.

Table 4: FRAME framework modification codes for modifications during the scale-up trial. 


\begin{tabular}{|c|c|c|c|c|c|}
\hline $\begin{array}{l}\text { Modification } \\
\text { Categories }\end{array}$ & Codes & $\begin{array}{l}\text { Physical } \\
\text { Activity } \\
\text { Practices } \\
\text { n (\%) }\end{array}$ & $\begin{array}{l}\text { Implementation } \\
\text { Support } \\
\text { Strategies } \\
\mathrm{n}(\%)\end{array}$ & $\begin{array}{l}\text { Evaluation } \\
\text { methods } \\
N(\%)\end{array}$ & $\begin{array}{l}\text { Total } \\
\text { (practices, } \\
\text { strategies, } \\
\text { whole } \\
\text { program } \\
\text { and } \\
\text { evaluation) } \\
\mathrm{n}(\%)^{\star \star}\end{array}$ \\
\hline \multirow{3}{*}{$\begin{array}{l}\text { Program } \\
\text { component?* }\end{array}$} & \multirow{2}{*}{$\begin{array}{l}\text { Implementation Support } \\
\text { Strategies }\end{array}$} & \multirow{3}{*}{$\begin{array}{l}\text { N/A } \\
3(100) \\
\text { N/A }\end{array}$} & \multirow{3}{*}{$\begin{array}{l}16(100) \\
\text { N/A } \\
\text { N/A }\end{array}$} & \multirow{3}{*}{$\begin{array}{l}\text { N/A } \\
\text { N/A } \\
1(100)\end{array}$} & \multirow{3}{*}{$\begin{array}{l}16(80) \\
3(15) \\
1(5)\end{array}$} \\
\hline & & & & & \\
\hline & Evaluation & & & & \\
\hline \multirow{4}{*}{$\begin{array}{l}\text { Proposed impact on } \\
\text { the project? }\end{array}$} & Positive & $2(67)$ & $13(81)$ & $0(0)$ & $15(79)$ \\
\hline & Negative & $1(33)$ & $3(19)$ & $0(0)$ & $4(21)$ \\
\hline & Null & $0(0)$ & $0(0)$ & $0(0)$ & $0(0)$ \\
\hline & Not applicable & $0(0)$ & $0(0)$ & $1(100)$ & 1 \\
\hline \multirow{3}{*}{$\begin{array}{l}\text { Relationship to } \\
\text { fidelity/core } \\
\text { elements? }\end{array}$} & Fidelity consistent & $3(100)$ & $16(100)$ & $\mathrm{N} / \mathrm{A}$ & $19(100)$ \\
\hline & Fidelity inconsistent & $0(0)$ & $0(0)$ & N/A & $0(0)$ \\
\hline & Not applicable & $0(0)$ & $0(0)$ & $1(100)$ & 1 \\
\hline \multirow{2}{*}{$\begin{array}{l}\text { Were modifications } \\
\text { systematic or } \\
\text { unsystematic? }\end{array}$} & Systematic & $0(0)$ & $2(13)$ & $0(0)$ & $2(10)$ \\
\hline & Unsystematic & $3(100)$ & $14(88)$ & $1(100)$ & $18(90)$ \\
\hline \multirow{2}{*}{$\begin{array}{l}\text { Were modifications } \\
\text { proactive or } \\
\text { reactive? }\end{array}$} & Proactive & $3(100)$ & $9(56)$ & $0(0)$ & $12(60)$ \\
\hline & Reactive & $0(0)$ & $7(44)$ & $1(100)$ & $8(40)$ \\
\hline \multirow{6}{*}{$\begin{array}{l}\text { Who participated in } \\
\text { the decision to } \\
\text { modify?*}\end{array}$} & Program Manager & $3(100)$ & $13(81)$ & $1(100)$ & $17(85)$ \\
\hline & Individual practitioners & $2(67)$ & $8(50)$ & $0(0)$ & $10(50)$ \\
\hline & \multirow{2}{*}{$\begin{array}{l}\text { Treatment/Intervention } \\
\text { Team }\end{array}$} & $1(33)$ & $2(13)$ & $0(0)$ & $3(15)$ \\
\hline & & $0(0)$ & $2(13)$ & $0(0)$ & $2(10)$ \\
\hline & \multirow{2}{*}{$\begin{array}{l}\text { Administrator } \\
\text { Recipients }\end{array}$} & $0(0)$ & $1(6)$ & $0(0)$ & $1(5)$ \\
\hline & & $0(0)$ & $1(6)$ & $0(0)$ & $1(5)$ \\
\hline \multirow{5}{*}{$\begin{array}{l}\text { What was the goal? } \\
\text { * }\end{array}$} & Improve fit with recipients & $2(67)$ & $5(31)$ & $0(0)$ & 7 (37) \\
\hline & Increase satisfaction & $0(0)$ & $6(38)$ & $0(0)$ & $6(32)$ \\
\hline & \multirow{2}{*}{$\begin{array}{l}\text { Improve } \\
\text { effectiveness/outcomes }\end{array}$} & $0(0)$ & $5(31)$ & $0(0)$ & $5(26)$ \\
\hline & & $0(0)$ & $4(25)$ & $0(0)$ & $4(21)$ \\
\hline & $\begin{array}{l}\text { Increase reach or } \\
\text { engagement }\end{array}$ & $0(0)$ & $4(25)$ & $0(0)$ & $4(21)$ \\
\hline
\end{tabular}




\begin{tabular}{|c|c|c|c|c|c|}
\hline & Increase retention & $1(33)$ & $0(0)$ & $0(0)$ & $1(5)$ \\
\hline & Improve feasibility & $0(0)$ & $1(6)$ & $0(0)$ & $1(5)$ \\
\hline & None & $0(0)$ & $0(0)$ & $1(100)$ & 1 \\
\hline & \multicolumn{5}{|l|}{ Not applicable } \\
\hline \multirow[t]{4}{*}{ What is modified? } & Content & $2(67)$ & $12(75)$ & $0(0)$ & $14(70)$ \\
\hline & Training and Evaluation & $1(33)$ & $4(25)$ & $1(100)$ & $6(30)$ \\
\hline & Contextual & $0(0)$ & $0(0)$ & $0(0)$ & $0(0)$ \\
\hline & $\begin{array}{l}\text { Implementation and scale- } \\
\text { up activities }\end{array}$ & $0(0)$ & $0(0)$ & $0(0)$ & $0(0)$ \\
\hline $\begin{array}{l}\text { Context } \\
\text { modifications are } \\
\text { made to what? }\end{array}$ & Not applicable & $3(100)$ & $16(100)$ & 1 (100) & 20 \\
\hline \multirow{4}{*}{$\begin{array}{l}\text { At what level of } \\
\text { delivery were } \\
\text { modifications } \\
\text { made? }\end{array}$} & \multirow{2}{*}{$\begin{array}{l}\text { Target Intervention Group } \\
\text { (all schools) }\end{array}$} & $3(100)$ & $11(69)$ & $1(100)$ & $15(75)$ \\
\hline & & $0(0)$ & $3(19)$ & $0(0)$ & $3(15)$ \\
\hline & $\begin{array}{l}\text { Cohort (Group of schools } \\
\text { sharing a characteristic) }\end{array}$ & $0(0)$ & $2(13)$ & $0(0)$ & $2(10)$ \\
\hline & \multicolumn{5}{|l|}{$\begin{array}{l}\text { Clinic Unit/level (individual } \\
\text { schools) }\end{array}$} \\
\hline \multirow{9}{*}{$\begin{array}{l}\text { What is the nature } \\
\text { of the content } \\
\text { modification?* }\end{array}$} & Adding elements & $0(0)$ & $5(31)$ & $0(0)$ & $5(36)$ \\
\hline & Tailoring/tweaking/refıning & $1(33)$ & $2(13)$ & $0(0)$ & $3(21)$ \\
\hline & \multirow{2}{*}{$\begin{array}{l}\text { Removing/skipping } \\
\text { elements }\end{array}$} & $1(33)$ & $1(6)$ & $0(0)$ & $2(14)$ \\
\hline & & $0(0)$ & $1(6)$ & $0(0)$ & $1(7)$ \\
\hline & $\begin{array}{l}\text { Lengthening/extending } \\
\text { elements }\end{array}$ & $0(0)$ & $1(6)$ & $0(0)$ & $1(7)$ \\
\hline & Substituting & $0(0)$ & $1(6)$ & $0(0)$ & $1(7)$ \\
\hline & \multirow{2}{*}{$\begin{array}{l}\text { Reordering of intervention } \\
\text { modules or segments }\end{array}$} & $0(0)$ & $1(6)$ & $0(0)$ & $1(7)$ \\
\hline & & $1(33)$ & $4(25)$ & $1(100)$ & 6 \\
\hline & Not applicable & & & & \\
\hline \multirow{4}{*}{$\begin{array}{l}\text { Reasons - socio- } \\
\text { political (i.e. broad } \\
\text { context)*}\end{array}$} & None (no reason) & $3(100)$ & $14(88)$ & $0(0)$ & $17(89)$ \\
\hline & Societal/cultural norms & $0(0)$ & $1(6)$ & $0(0)$ & $1(5)$ \\
\hline & Historical Context & $0(0)$ & $1(6)$ & $0(0)$ & $1(5)$ \\
\hline & Not applicable & $0(0)$ & $0(0)$ & $1(100)$ & 1 \\
\hline \multirow{4}{*}{$\begin{array}{l}\text { Reasons - } \\
\text { organization/setting } \\
\text { (i.e. PA4E1 } \\
\text { Implementation } \\
\text { Team)* }\end{array}$} & \multirow[t]{2}{*}{$\begin{array}{l}\text { Available resources (funds, } \\
\text { staff, tech, space) }\end{array}$} & $1(33)$ & $13(81)$ & $0(0)$ & $14(74)$ \\
\hline & & $2(67)$ & $3(19)$ & $0(0)$ & $5(26)$ \\
\hline & None (no reason) & $0(0)$ & $1(6)$ & $0(0)$ & $1(5)$ \\
\hline & $\begin{array}{l}\text { Social context } \\
\text { Not applicable }\end{array}$ & $0(0)$ & $0(0)$ & $1(100)$ & 1 \\
\hline
\end{tabular}




\begin{tabular}{|llllll|}
$\begin{array}{l}\text { Reasons - provider } \\
\text { (i.e. Local Health } \\
\text { District)* }\end{array}$ & None (no reason) & $3(100)$ & $16(100)$ & $0(0)$ & $19(100)$ \\
& Not applicable & $0(0)$ & $0(0)$ & $1(100)$ & 1 \\
$\begin{array}{l}\text { Reasons - recipient } \\
\text { (i.e. schools and in- }\end{array}$ & None (no reason) & $1(33)$ & $8(50)$ & $0(0)$ & $9(47)$ \\
$\begin{array}{l}\text { School } \\
\text { Champions)* }\end{array}$ & Motivation and readiness & $2(67)$ & $5(31)$ & $0(0)$ & $7(37)$ \\
& Physical capacity & $0(0)$ & $3(19)$ & $0(0)$ & $3(16)$ \\
& Access to resources & $0(0)$ & $2(13)$ & $0(0)$ & $2(11)$ \\
& Cultural or religious norms & $0(0)$ & $1(6)$ & $0(0)$ & $1(5)$ \\
& Not applicable & $0(0)$ & $0(0)$ & $1(100)$ & 1 \\
\hline
\end{tabular}

\section{Footnotes}

Percentages are rounded, so may not sum to $100 \%$.

Additional File 3 outlines each individual modification in detail and includes the full set of codes as outlined in the methods.

*Percentages may not sum to $100 \%$, and $n$ values may not add up to the number of modifications $(N=20)$ because multiple codes within this category may be applied to each modification.

**'Not applicable (N/A)' category not included in denominator to calculate percentages.

\section{Figures}




\begin{tabular}{|c|c|}
\hline Efficacy Trial & Scale-up Trial \\
\hline 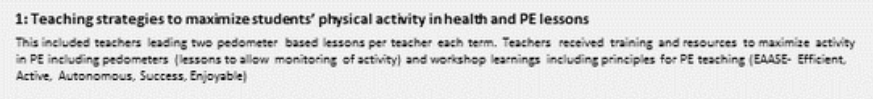 & 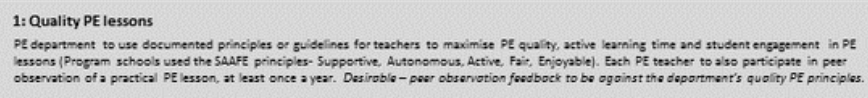 \\
\hline 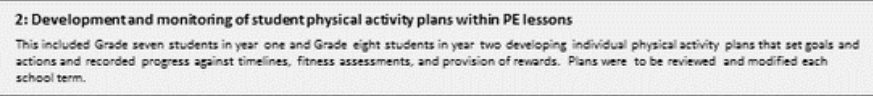 & 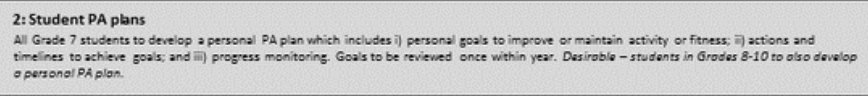 \\
\hline 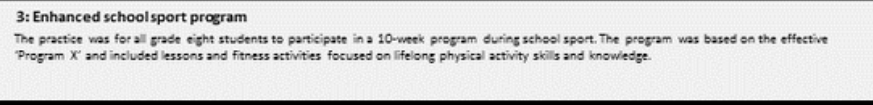 & 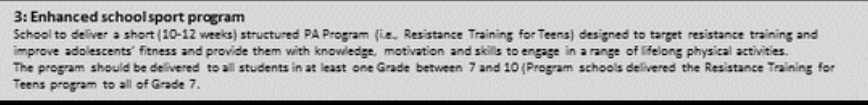 \\
\hline 4: Development/ modification of school policies & 5: School PA policy or procedure \\
\hline $\begin{array}{l}\text { Sehools were to develop or mosify eisting school poricies that aimed to enhanse student physical activity through collaboration between the head } \\
\text { PE teacher, in-school consultant (support strategy 1), and school executive. }\end{array}$ & 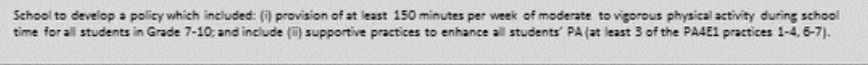 \\
\hline 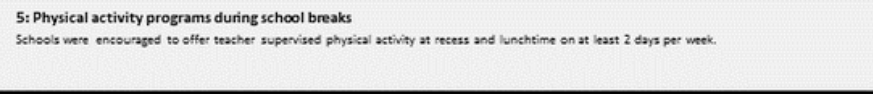 & 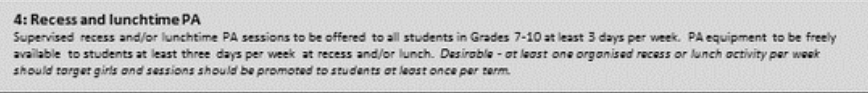 \\
\hline $\begin{array}{l}\text { 6: Promotion of community physical activity providers (community links) } \\
\text { Schools hosted a physical activity eahibition that promoted local physical activity providers to students in Grade } 8 \text {. }\end{array}$ & 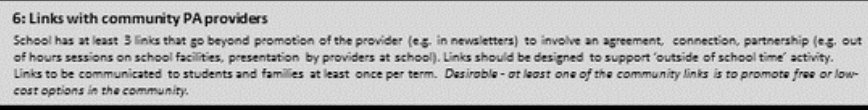 \\
\hline 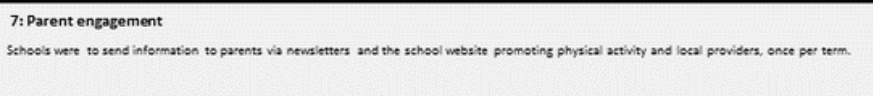 & 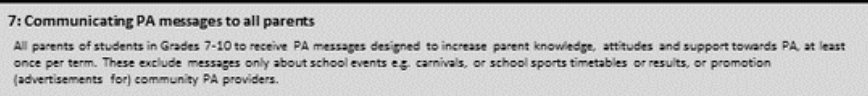 \\
\hline
\end{tabular}

\section{Figure 1}

Summary of the physical activity practices in the PA4E1 efficacy trial $(24-26,28)$ and the PA4E1 scale-up trial $(29-$ 31).

\begin{tabular}{|c|c|}
\hline Implementat & rt Strategies \\
\hline $\begin{array}{l}\text { 1: In-School Consultant } \\
\text { A trained PE teacherwas placed within each school (in-school physical activity consultant) for } 1 \text { day per week over the } \\
\text { intervention period to support intervention implementation. }\end{array}$ & $\begin{array}{l}\text { 2: Embedded school-staft: in-School Champions } \\
\text { An exisiting schoolPE teacher is tobe allocated the role of in-School Championto support implementation. The position is } \\
\text { funded by the NSWD Department of Health for half a day per week ( } \$ 3504 \text { UD perfortnight). } \\
\text { 3: External Implementation Support } \\
\text { A Health Promotion Support Officer (ideally with PE teacher training) is appointed to support schools with the program, co. } \\
\text { located within the relevant local health district Support is offered in the form of face-to-face site visits, phone calls and emails } \\
\text { according to a schedule (outlined in detal elsewhere). }\end{array}$ \\
\hline $\begin{array}{l}\text { 2: Leadership and Committee } \\
\text { A school committee was etrablished, including school executive, Head PE teacher, communityregresentative, student } \\
\text { representative and parent representative, or responsibility was added to an existing commintee, to lead and oversee the } \\
\text { intervention. Schools executives were asked to sign a partnership agreement Commintee to meet once per term. }\end{array}$ & $\begin{array}{l}\text { 1: Executive and leadership support } \\
\text { PA4E1 partnership agreementto be signed by school executive New or existing school committee formed to oversee the } \\
\text { program. The school committee should be inclusive of an in.School Champion and school executive to oversee the program and } \\
\text { should meet atleast once per term. }\end{array}$ \\
\hline $\begin{array}{l}\text { 3: Teacher Training } \\
\text { PE teachers were offered three two-hourface-toface practice leaming workshops (all schools together) focused on delivery of } \\
\text { lessons to increase students' MVPA. All PE teachers and teachers involved in the delivery of the enhanced school sports program } \\
\text { were invited to face-to-face training (at least once PE teacher per school to attend. all invited). }\end{array}$ & $\begin{array}{l}\text { 4: Teacher professional learning } \\
\text { In-School Championsto to atrand face-toface training at the start of the program, half-way through ( } 12 \text { months) andprior to } \\
\text { finishing the program ( } 24 \text { months). Online videos ( } 6 \times 10 \text { minutes) with knowledgecheck quizzes delivered to in-School Champions } \\
\text { and PE Teachers via the programwebsite. Enhanced school sport training offered to those involved in it's delivery. School PA } \\
\text { policy training offered to inschoolchampions of Government schools. }\end{array}$ \\
\hline $\begin{array}{l}\text { 4: Resources } \\
\text { Schools were provided with AUDS11,874 worth of resources. This included a paper-based manual outlining all physical activity } \\
\text { intervention strategies and associated materials; approximately AUD } 60000 \text { of physical activity equipment (e.g, pedometers, } \\
\text { resistance devices, games consoles, equipment boxes); and promotional materiats for te achers (e.g, shirt/lanyards) and students } \\
\text { (e.g., balls, water bottles). }\end{array}$ & $\begin{array}{l}\text { 5: Resources } \\
\text { Electronic resources delivered via the program website. Limited amounts of equipment and physical resources to be sent to } \\
\text { schools, including a } 100 \text { AUD equipmentvoucher, } 5 \text { gymsticks and PAAE1 SAAFE posters }\end{array}$ \\
\hline $\begin{array}{l}\text { 5. Prompts } \\
\text { An in-school consultant provided prompts to teaching staff to implement the intervention strategies via e-mail, electronic } \\
\text { calendar reminders, and inface-to-facemeetings. }\end{array}$ & $\begin{array}{l}\text { 6: Provision of prompts and reminders } \\
\text { Automated messages to be sent each term to in-School Champions to promptcompletion of termly surveys and also professional } \\
\text { learning videos. Additionally, contact to be made bySupport Officers to in-School Champions according to a schedule (outined in } \\
\text { detail elsewhere). }\end{array}$ \\
\hline $\begin{array}{l}\text { 6. Feedback Reports } \\
\text { Records kept by the in-school consultant were the basis of quarterly intervention implementation feedback reports (on how was } \\
\text { the school progressing with the practices) provided via email and hard copy to Principals and Head of PE. }\end{array}$ & $\begin{array}{l}\text { 7: Implementation performance monitoring and feedback } \\
\text { In-School Championto complete termly surveys and received an automated feedback report via email, generated from the } \\
\text { responses to the termly survey on the program website. This report al so to be sentto school Principals via email. }\end{array}$ \\
\hline
\end{tabular}




\section{Figure 2}

Summary of the implementation support strategies offered to schools in the PA4E1 efficacy trial $(24-26,28)$ and the PA4E1 scale-up trial (29-31).

\section{Supplementary Files}

This is a list of supplementary files associated with this preprint. Click to download.

- AdditionalFile1.docx

- AdditionalFile2.docx

- AdditionalFile3.docx 